\title{
Analisis Strategi Mahasiswa dalam Menentukan Turunan Fungsi dengan Metode Diferensiasi Logaritmik
}

\author{
Puspita Sari ${ }^{1}$ \\ ${ }^{1}$ Universitas Negeri Jakarta, puspitasari@unj.ac.id
}

\begin{abstract}
ABSTRAK
Kalkulus merupakan salah satu cabang matematika yang berperan penting dalam bidang ilmu lainnya. Konsep dasar kalkulus yang terdiri dari limit, turunan, dan integral merupakan konsep yang saling berkaitan satu sama lain. Terlebih lagi, penguasaan strategi dalam menentukan turunan dan integral suatu fungsi merupakan fondasi bagi ilmu matematika yang lebih lanjut. Penelitian ini bertujuan untuk mengeksplorasi dan menganalisa metode diferensiasi logaritmik yang digunakan oleh mahasiswa dalam menyelesaikan turunan fungsi tertentu. Data diperoleh dari hasil analisis dokumen, wawancara, serta observasi mengenai proses berpikir mahasiswa, kesulitan yang dihadapi, serta alasan penggunaan metode diferensiasi logaritmik dalam menentukan turunan fungsi. Hasil analisa menunjukkan bahwa mahasiswa cenderung menggunakan metode diferensiasi logaritmik jika menemui jenis fungsi rasional yang melibatkan pangkat pecahan pada setiap faktornya, maupun jika terdapat dua atau lebih faktor di pembilang dan penyebutnya, demikian pula pada jenis fungsi perkalian yang memiliki lebih dari dua faktor. Berdasarkan hasil analisa, metode diferensiasi logaritmik ini selain dapat digunakan untuk mempermudah penyelesaian turunan, juga untuk dapat menghindari kesalahan dalam menggunakan aturan rantai pada jenis fungsi tertentu.
\end{abstract}

Kata Kunci: diferensiasi logaritmik, kalkulus, turunan, derivatif, logaritma.

\begin{abstract}
Calculus is one of subject in mathematics which has important role for other disciplines. The fundamental concept of calculus consists of limit, derivative, and integral from which each concept is interrelated. Moreover, the mastery of the strategy on finding the derivative and the integral of the given function is the fundamental basic for advance mathematics. This study aims for exploring ans analyzing the logarithmic method used by the undergraduate students in solving particular derivative. The data are obtained from the analysis of the document, interview, and observation toward students' difficulty in the thinking process, also the reasoning on why the logarithmic differentiation is used to find the derivative of the function. The analysis suggest that the undergraduate students tend to use logarithmic differentiation when the function given is a rational function with fraction power on both each factors and two or more factors in both numerator and denominator. Furthermore, the method also used in the multiplication function with more than two factors. Based on the analysis result, this logarithmic differentiation
\end{abstract}


method is not only able to help in finding the derivation solution easier, but also able

to avoid mistakes that occur while using chain rule in particular function

Keywords: logarithmic differentiation, calculus, derivative, logarithm.

\section{Pendahuluan}

Kalkulus merupakan salah satu cabang ilmu matematika yang memiliki peran penting tidak hanya dalam ilmu matematika itu sendiri, melainkan juga dalam bidang ilmu lainnya seperti pada bidang ekonomi, fisika, kimia, dan sebagainya. Kalkulus diferensial yang membahas mengenai konsep derivatif atau turunan dan aturan pencarian turunan (diferensiasi) serta aplikasinya merupakan salah satu mata kuliah wajib bagi mahasiswa matematika dan sains pada tahun pertama perkuliahan. Diantara aplikasi konsep turunan (derivatif) adalah untuk menentukan nilai ekstrim (maksimum atau minimum) dari suatu fungsi serta untuk mensketsa grafik fungsi. Sementara itu, aplikasi konsep turunan pada bidang ilmu lainnya adalah untuk menentukan tingkat petumbuhan organisme pada bidang ilmu biologi ; menentukan keuntungan marjinal pada bidang ilmu ekonomi ; menentukan kecepatan sesaat dan kerapatan kawat pada bidang ilmu fisika ; serta menentukan tingkat disolusi pada bidang ilmu kimia [1]. Dengan demikian, penguasaan konsep kalkulus salah satunya pada teknik penurunan atau diferensiasi perlu mendapatkan perhatian penting dalam pembelajaran kalkulus di kelas.

Berbagai penelitian mengenai kesulitan dan pemahaman konsep turunan mahasiwa maupun penelitian tentang penggunaan teknologi dan pendekatan pembelajaran yang inovatif dalam pembelajaran konsep kalkulus diferensial telah menjadi pusat perhatian dan trend penelitian belakangan ini $[2,3,4,5]$ namun masih sedikit penelitian yang dilakukan untuk mengeksplorasi strategi mahasiswa dan kesulitannya dalam menggunakan aturan pencarian turunan ( aturan diferensiasi).

Berbagai aturan pencarian turunan atau aturan diferensiasi dirumuskan dalam teorema yang telah dibuktikan dan dijabarkan secara terperinci pada berbagai buku teks kalkulus, diantaranya adalah aturan perkalian, aturan pembagian, aturan pangkat, dan sebagainya. Aturan tersebut dapat dengan mudah digunakan untuk menentukan turunan fungsi pada jenis fungsi polinom maupun fungsi rasional, namun tidak demikian halnya dengan fungsi transenden. Terdapat aturan khusus yang digunakan dalam menentukan turunan fungsi transenden, misal turunan fungsi trigonometri, turunan fungsi eksponen, turunan fungsi logaritma natural maupun fungsi logaritma umum. Pada pembahasan yang lebih lanjut, metode diferensiasi logaritmik diperkenalkan untuk mempermudah menentukan turunan fungsi yang lebih kompleks. Penerapan metode diferensiasi logaritmik dengan menggunakan sifat-sifat logaritma dapat mempermudah penyelesaian soal turunan fungsi tertentu, yaitu fungsi yang melibatkan pembagian, perkalian, dan perpangkatan [1].

Berdasarkan pengamatan yang dilakukan pada mahasiswa program studi Matematika yang mengambil mata kuliah Kalkulus Diferensial di semester ganjil tahun 2017/2018, metode diferensiasi logaritmik muncul sebagai strategi penurunan alternatif yang dapat digunakan tidak hanya untuk fungsi transenden namun juga untuk jenis fungsi polinom dan rasional serta fungsi pangkat tertentu. Beberapa mahasiswa menunjukkan kecenderungan menggunakan metode diferensiasi logaritmik dalam menentukan turunan fungsi tertentu.

Dengan demikian, penelitian ini bertujuan untuk menginvestigasi kesulitan yang dialami mahasiswa saat menyelesaikan turunan fungsi dengan menggunakan metode diferensiasi logaritmik, serta untuk menjelaskan mengapa mahasiswa cenderung memilih 
metode diferensiasi logaritmik, sehingga dapat dijelaskan pula lebih lanjut mengenai karakteristik fungsi yang dapat diturunkan secara lebih mudah dengan menggunakan metode diferensiasi logaritmik. Secara lebih spesifik, penelitian ini akan menjawab pertanyaan penelitian sebagai berikut:

1. Apa kesulitan yang muncul dalam menggunakan metode diferensiasi logaritmik saat menyelesaikan turunan fungsi?

2. Mengapa mahasiswa cenderung memilih metode diferensiasi logaritmik dalam menyelesaikan turunan fungsi tersebut?

3. Apa saja karakteristik fungsi yang dapat diturunkan secara lebih mudah dengan menggunakan metode diferensiasi logaritmik?

\section{Definisi Turunan dan Aturan Diferensiasi}

Konsep turunan yang merupakan inti dalam ilmu kalkulus diferensial didefinisikan sebagai laju perubahan suatu fungsi yang pertama kali diperkenalkan pada masalah geometris dalam menentukan gradien garis singgung kurva di suatu titik, dan kemudian pada masalah fisika dalam menentukan kecepatan suatu objek pada suatu waktu $[3,1,6]$. Jika diketahui suatu fungsi $f$ yang terdefinisi pada suatu domain dengan $x$ dan $(x+h)$ adalah titik -titik yang terletak pada domain maka $f^{\prime}$ disebut sebagai fungsi turunan dari $f$ di $x$ yang merupakan nilai limit dari $\frac{f(x+h)-f(x)}{h}$ ketika nilai $h$ mendekati nol. Jika nilai limit tersebut ada, maka fungsi $f$ dikatakan terdiferensiasikan di $x$. Secara formal, berikut adalah definisi fungsi turunan $f^{\prime}$ (dibaca $f$ aksen):

Turunan dari fungsi $f$ adalah fungsi $f^{\prime}$ yang nilainya untuk setiap $x$ adalah

$$
f^{\prime}(x)=\lim _{h \rightarrow 0} \frac{f(x+) \quad f(x)}{}
$$

Proses menentukan turunan suatu fungsi disebut juga sebagai diferensiasi. Diferensiasi dapat dilakukan tanpa menggunakan definisi seperti contoh diatas, melainkan menggunakan teorema - teorema atau aturan yang telah dibuktikan kebenarannya menggunakan definisi turunan. Berikut adalah teorema yang dapat digunakan dalam menentukan turunan fungsi [1]

1. Aturan Fungsi Konstan Jika $f(x)=k, k$ adalah konstanta, maka untuk setiap $x, D_{x}(k)=0$.

2. Aturan Fungsi Identitas Jika $f(x)=x$, maka untuk setiap $x, D_{x}(x)=1$.

3. Aturan Pangkat Jika $f(x)=x^{n}, n$ adalah bilangan bulat positif, maka $D_{x}\left(x^{n}\right)=n x^{n-1}$.

4. Aturan Pengali Konstanta

5. Aturan Jumlah

$$
D_{x}[k \cdot f(x)]=k \cdot D_{x} f(x)
$$

6. Aturan Selisih

$$
D_{x}[f(x)+g(x)]=D_{x} f(x)+D_{x} g(x)
$$

7. Aturan Perkalian

$$
D_{x}[f(x) \quad g(x)]=D_{x} f(x) \quad D_{x} g(x)
$$

$$
D_{x}[f(x) g(x)]=f(x) D_{x} g(x)+g(x) D_{x} f(x)
$$

8. Aturan Pembagian 


$$
D_{x}\left[\frac{f(x)}{g(x)}\right]=\frac{g(x) D_{x} f(x) \quad f(x) D_{x} g(x)}{g^{2}(x)}
$$

\section{Metode Diferensiasi Logaritmik}

Metode diferensiasi logaritmik adalah metode diferensiasi yang menggunakan sifat dan turunan dari fungsi logaritma natural, sebagai upaya untuk mempersingkat langkah yang ditempuh dalam menentukan turunan dari fungsi yang melibatkan pembagian, perkalian, dan perpangkatan (Varberg et al., 2006, hal 329). Dalam menggunakan metode diferensiasi logaritmik, kedelapan aturan diferensiasi yang telah dijelaskan sebelumnya tidaklah cukup. Metode diferensiasi logaritmik menggunakan turunan dari fungsi logaritma natural, yaitu:

$$
D_{x}(\ln x)=\frac{1}{x} \quad, x>0
$$

Dengan menggunakan aturan rantai, jika $u=f(x)>0$, dan $f(x)$ terdiferensiasikan, maka

$$
D_{x}(\ln u)=\frac{1}{u} D_{x} \mathrm{u}
$$

Lebih lanjut lagi, berikut adalah sifat -sifat logaritma natural yang digunakan dalam metode diferensiasi logaritmik, jika $a$ dan $b$ adalah bilangan positif dan $r$ sembarang bilangan rasional, maka berlaku:

$$
\begin{array}{cl}
\text { i. } & \ln 1=0 \\
\text { ii. } & \ln \frac{a}{b}=\ln a \quad \ln b \\
\text { iii. } & \ln a b=\ln a+\ln b \\
\text { iv. } & \ln a^{r}=r \ln a
\end{array}
$$

Berikut adalah contoh penerapan metode diferensiasi logaritmik dalam menentukan turunan fungsi: Tentukan $\frac{d y}{d x}$ untuk fungsi berikut:

$$
y=\frac{\sqrt{x+13}}{\left(\begin{array}{ll}
x & 4) \sqrt[3]{2 x+1}
\end{array}\right.}
$$

Pada soal ini, fungsi $y$ merupakan fungsi rasional yang melibatkan pembagian $\sqrt{x+13}$ dengan $\left(\begin{array}{ll}x & 4\end{array}\right) \sqrt[3]{2 x+1}$. Sehingga, soal ini dapat diselesaikan dengan menggunakan aturan pembagian

$$
D_{x}\left[\frac{f(x)}{g(x)}\right]=\frac{g(x) D_{x} f(x) \quad f(x) D_{x} g(x)}{g^{2}(x)}
$$

Namun demikian, jika diperhatikan lebih lanjut, penyebut dari fungsi rasional tersebut terdiri dari dua faktor, yaitu $\left(\begin{array}{ll}x & 4\end{array}\right)$ dan $\sqrt[3]{2 x+1}$, sehingga diperlukan aturan perkalian dalam menentukan turunan dari fungsi pada penyebut. Sementara itu, dengan menggunakan metode diferensiasi logaritmik maka aturan pembagian dan perkalian dapat dihindari. Berikut adalah langkah-langkah penyelesaian dengan metode diferensiasi logaritmik:

$$
\text { - } y=\frac{\sqrt{x+13}}{(x-4) \sqrt[3]{2 x+1}}
$$


- $\quad \ln y=\ln \frac{\sqrt{x+13}}{(x-4) \sqrt[3]{2 x+1}}$

- $\ln y=\ln \sqrt{x+13}[\ln (x \quad 4)+\ln \sqrt[3]{2 x+1}]$ (sifat ii logaritma natural)

- $\quad \ln y=\frac{1}{2} \ln (x+13) \quad \ln (x \quad 4) \quad \frac{1}{3} \ln (2 x+1) \quad$ (sifat iv logaritma natural)

- $\frac{1}{y} \cdot \frac{d y}{d x}=\frac{1}{2(x+13)} \quad \frac{1}{(x-4)} \quad \frac{2}{3(2 x+1)}$

(melakukan turunan pada kedua ruas, ruas kiri menggunakan metode turunan implisit, ruas kanan menggunakan turunan fungsi logaritma natural)

- $\frac{d y}{d x}=\frac{(x+13)^{1 / 2}}{(x-4)(2 x+1)^{1 / 3}}\left[\begin{array}{lll}\frac{1}{2(x+13)} & \frac{1}{(x-4)} & \frac{2}{3(2 x+1)}\end{array}\right]$

Dengan demikian, $\frac{d y}{d x}=\frac{10 x^{2}+21 x-118}{6(x+13)^{\frac{1}{2}}(x-4)^{2}(2 x+1)^{\frac{4}{3}}}$ merupakan turunan fungsi $y=\frac{\sqrt{x+13}}{(x-4) \sqrt[3]{2 x+1}}$

\section{Metode Penelitian}

Penelitian ini merupakan penelitian studi kasus dengan subjek penelitian sebanyak dua orang mahasiswa program studi Matematika FMIPA UNJ angkatan 2017 yang sedang mengikuti mata kuliah kalkulus diferensial pada tahun ajaran 2017/2018. Kriteria pemilihan subjek penelitian berdasarkan kecenderungan mahasiswa dalam menggunakan metode diferensiasi logaritmik yang dilihat dari hasil tes tertulis yang diberikan kepada 50 mahasiswa program studi Matematika FMIPA UNJ yang mengambil mata kuliah kalkulus diferensial pada tahun ajaran 2017/2018. Butir tes yang diberikan sebanyak 6 butir soal yang meliputi soal turunan fungsi transenden.

Berdasarkan jawaban mahasiswa pada soal tes tersebut, dipilih dua mahasiswa yang bernama SP1 dan SP2 yang menunjukkan kecenderungan dalam menggunakan metode diferensiasi logaritmik untuk menentukan turunan pada beberapa butir tes soal tersebut. Dengan demikian, fokus pada penelitian ini adalah metode diferensiasi logaritmik dalam menentukan turunan fungsi tertentu. Hal tersebut sesuai dengan pernyataan dalam [7] bahwa:

"case studies focus on one (or just a few) instances of a particular phenomenon with a view to providing an in-depth account of events, relationships, experiences or processes occuring in that particular instance" (hal.52)

Untuk dapat menjawab pertanyaan penelitian tersebut akan digunakan beberapa metode pengumpulan data, yaitu wawancara dan analisis dokumen. Tujuan dari wawancara adalah untuk mendapatkan klarifikasi serta menggali informasi dari kedua mahasiswa tentang cara berpikir mereka dalam menyelesaikan soal-soal yang diberikan. Sementara itu, dokumen yang dianalisis terdiri dari jawaban tertulis kedua mahasiswa pada tes pertama dan tes lanjutan, serta transkrip wawancara. Tes pertama selain digunakan untuk memilih subjek penelitian juga digunakan sebagai salah panduan dalam menyusun soal-soal pada tes lanjutan, dimana strategi yang digunakan dan kesulitan yang muncul dari mahasiswa akan dapat diobservasi secara lebih mendalam. Soal tes lanjutan disusun berdasarkan hasil kajian literatur mengenai metode diferensiasi logaritmik yang bertujuan untuk memunculkan metode ini dalam penyelesainnya, meskipun tidak menutup kemungkinan untuk tetap dapat menggunakan cara lain dalam penyelesaian soalnya. 


\section{Analisis Hasil Penelitian}

Hasil penelitian ini akan dideskripsikan secara kualitatif berdasarkan data yang diperoleh dari hasil tes tertulis dan hasil wawancara, maupun hasil observasi selama wawancara. Berdasarkan hasil tes maupun wawancara diperoleh cara berpikir mahasiswa dalam menggunakan metode diferensiasi logaritmik serta kesulitan yang dihadapi. Berikut adalah soal yang diberikan kepada kedua subjek penelitian sebelum wawancara berlangsung:

Tentukan turunan fungsi berikut:
1. $y=x^{2}(1$
$x)^{3} e^{-x}$
2. $y=x^{\ln x}$
3. $y=\sin ^{2} x+2^{\sin x}$
4. $y=(\cos x)^{x^{5}}$
5. $y=x \sqrt{x+1}$
6. $y=\frac{\left(x^{2}-1\right)^{3}}{x^{2}+1}$
7. $y=\sqrt{\frac{3 x+2}{2 x-1}}$

Ketujuh soal diatas dipilih dengan tujuan agar dapat mengeksplorasi strategi diferensiasi yang digunakan oleh mahasiswa dalam penyelesaiannya. Instruksi pada soal adalah menentukan turunan dari rumus fungsi yang diberikan, dengan demikian mahasiswa akan fokus menyelesaikan turunan fungsi dengan menggunakan metode yang tercepat dan termudah. Soal nomor 1 dan 5 dapat diselesaikan dengan menggunakan aturan perkalian atau dengan metode diferensiasi logaritmik. Soal nomor 6 dan 7 dapat diselesaikan dengan aturan pembagian maupun dengan metode diferensiasi logaritmik. Namun, untuk soal nomor 2, 3, dan 4 hanya dapat diselesaikan dengan menggunakan metode diferensiasi logaritmik.

Meskipun nomor 1, 5, 6, dan 7 dapat diselesaikan dengan aturan perkalian dan pembagian tanpa menggunakan metode diferensiasi logaritmik, namun pada soal nomor satu terdapat beberapa hal yang perlu diperhatikan. Pada soal nomor satu, terdapat tiga faktor pada fungsi y, sehingga jika menggunakan aturan perkalian $y^{\prime}=u^{\prime} v+u v^{\prime}$, maka ketiga faktor tersebut dimisalkan sebagai $u, v$ dan $w$, sehingga aturan perkalian tersebut perlu disesuaikan kembali, sehingga pengerjaan soal akan cenderung lebih lama dan perlu ke hati-hatian. Pada soal nomor lima terdapat dua faktor dan dapat menggunakan aturan perkalian, namun pada salah satu faktornya terdapat tanda akar sehingga diperlukan kecermatan saat menentukan turunan faktor tersebut.

Di bawah ini adalah analisa data yang diperoleh dari hasil analisis dokumen dan wawancara terhadap dua mahasiswa sebagai partisipan, yaitu SP1 dan SP2. Analisa akan diberikan sesuai dengan pertanyaan penelitian yang diajukan.

\subsection{Kesulitan dalam menggunakan metode diferensiasi logaritmik saat menyelesaikan turunan fungsi.}

Berdasarkan data yang diperoleh, gambar 1 dibawah ini menunjukkan beberapa kesulitan yang dialami oleh SP1. 


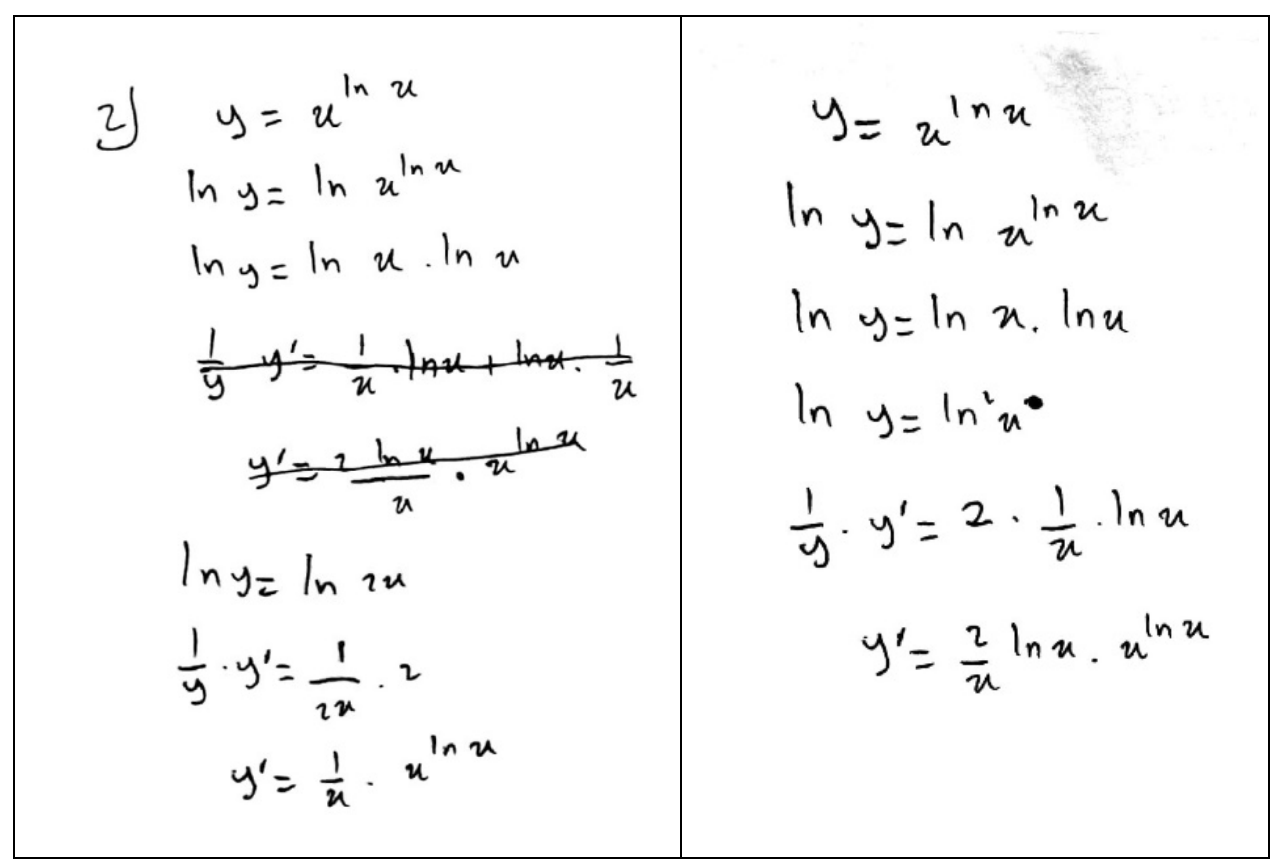

Gambar 1

Gambar 2

Gambar 1 baris ketiga dan keempat menunjukkan bahwa SP1 mungkin menggunakan $" \ln a \cdot \ln b=\ln (a+b)$ " saat menyimpulkan bahwa "'ln $x \cdot \ln x=\ln 2 x "$ yang mana persamaan tersebut tidak berlaku untuk logaritma. Hal ini mungkin terjadi karena SP1 salah mengingat sifat logaritma penjumlahan " $\ln a b=\ln a+\ln b "$. Setelah diberikan pertanyaan arahan maka SP1 dapat memperbaiki miskonsepsi nya mengenai sifat logaritma tersebut dan mampu menyelesaikan turunan fungsi $y=x^{\ln x}$ dengan benar (Gambar 2).

Miskonsepsi yang sama terulang kembali pada soal nomor tiga yang dikerjakan paling terakhir, transkrip wawancara di bawah ini menunjukkan bahwa SP1 menganggap bahwa ada sifat logaritma yang menyatakan $" \ln a \cdot \ln b=\ln (a+b) "$. Bentuk kesalahan ini merupakan salah satu kesalahan yang umum terjadi [8]

\begin{tabular}{|c|c|}
\hline \multicolumn{2}{|c|}{ Peneliti: “nomor tiga ... gimana nih?"(lihat gambar 3 di bawah) } \\
\hline SP1: & “Sama, saya pakai ln juga." \\
\hline Peneliti: & (memeriksa selama satu menit, kemudian bertanya) \\
\hline & "Nah, ini ada yang keliru gak kira-kira" \\
\hline SP1: & (diam dan ber \\
\hline Peneliti: & "Sifat $\ln$ yang mana yang kamu pakai?" \\
\hline SP1: & "Mmm... In yang penjumlahan jadi perkalian." \\
\hline Peneliti: & "bisa?" \\
\hline SP1: & "Yang $\ln$ dikurung a tambah $b$, jadi $\ln$ a kali $\ln b . "$ \\
\hline Peneliti: & $\begin{array}{l}\text { "Ibu tulis ya?" (Peneliti menulis sifat yang dimaksud oleh SP1, } \\
{[\ln (a+b)=\ln a \cdot \ln b] \text {, untuk memastikan sifat logaritma yg }} \\
\text { digunakan, kemudian kembali bertanya) "Ada?" }\end{array}$ \\
\hline SP1: & (sambil sedikit tertawa) "Setahu saya ada sih Bu." \\
\hline
\end{tabular}

Pada gambar 3. terlihat di baris kedua dan ketiga bahwa SP1 menyimpulkan $\ln \left(\sin ^{2} x+2^{\sin x}\right)=\ln \sin ^{2} x \cdot \ln 2^{\sin x}$. Sehingga dapat dikatakan bahwa kesulitan yang muncul saat menggunakan metode diferensiasi logaritmik adalah karena kurangnya 
pemahaman mahasiswa mengenai sifat-sifat logaritma yang digunakan dalam penyelesaian turunan.

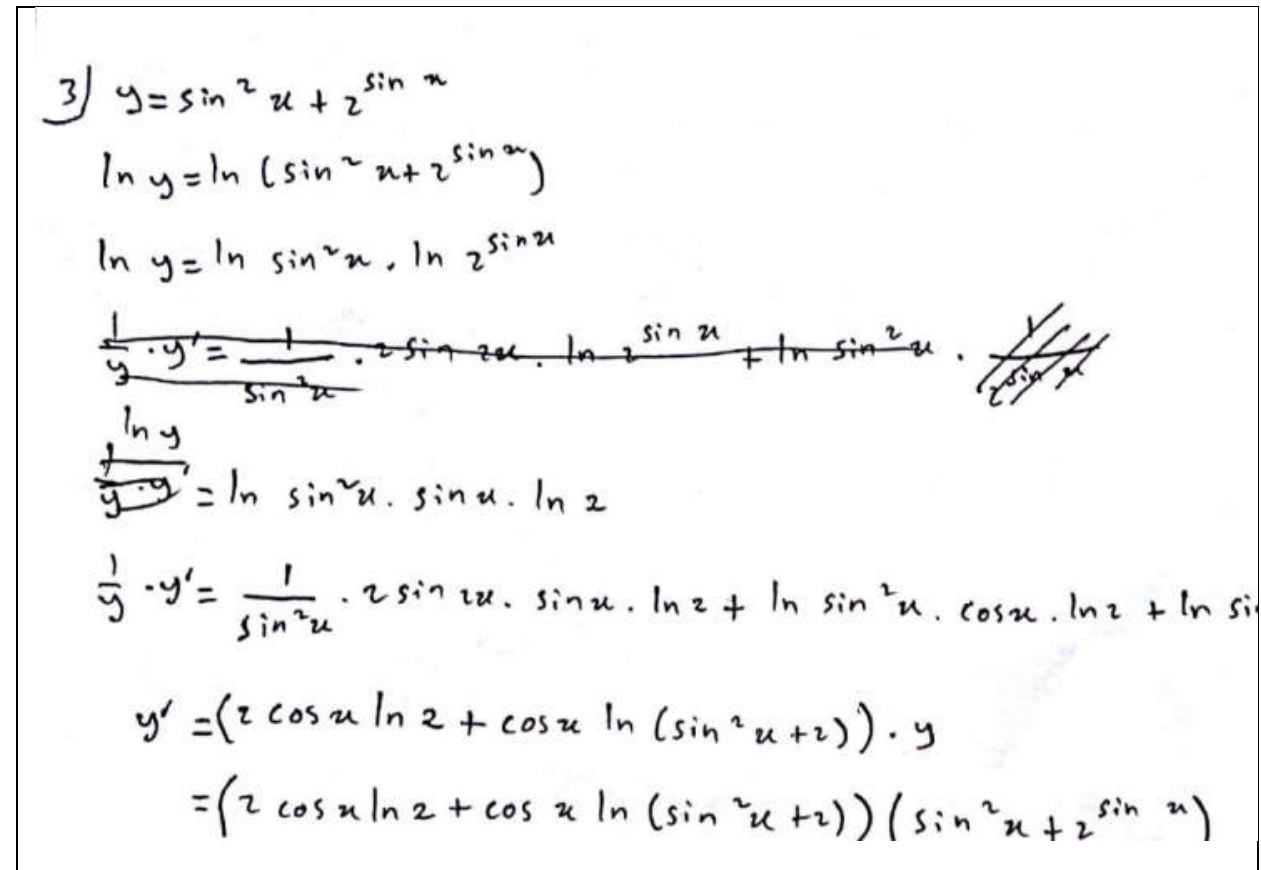

Gambar 3

Pada soal yang berbeda juga terlihat kesulitan SP1 dalam menggunakan sifat logaritma yang lain, yaitu sifat pangkat logaritma, dimana $r$ adalah eksponen dan $a$ adalah basis logaritma "In $a^{r}=r \ln a$ ". Kekeliruan dalam mengidentifikasi basis logaritma dan eksponen pada suatu bentuk logaritma mengakibatkan kesalahan yang muncul seperti pada gambar 4 di bawah ini. Bentuk $\sqrt{x}$ pada ekspresi ln $\cos e^{\sqrt{x}}$ bukanlah merupakan eksponen untuk basis $\cos e$.

$$
\text { 2. } \begin{aligned}
\frac{\partial}{\partial x}\left(\cos e^{\sqrt{u}}\right) \rightarrow & y=\cos e^{\sqrt{x}} \\
\ln y & =\ln \cos e^{\sqrt{x}} \\
\frac{\ln y}{y} & =e^{\sqrt{x}} \ln \cos \left(e^{\sqrt{x}}\right) \\
\frac{1}{y} \cdot y^{\prime} & =\frac{1}{2 \sqrt{x}} \cdot \ln \cos e^{\sqrt{x}}+\sqrt{x} \cdot \frac{1}{\cos e^{\sqrt{x}}} .
\end{aligned}
$$

\section{Gambar 4}

Pada penyelesaian soal di bawah ini (gambar 5), SP1 menggunakan metode diferensiasi logaritmik dalam menentukan turunan dari fungsi $y=x^{2}\left(\begin{array}{ll}1 & x\end{array}\right)^{3} e^{-x}$. Pada baris keempat, yaitu baris yang dicoret, terlihat bahwa SP1 menunjukkan kesalahan saat menurunkan fungsi $\ln x^{2}$ dan $\ln \left(\begin{array}{ll}1 & x\end{array}\right)^{3}$. Namun demikian kesalahan tersebut dapat diatasi, dan dengan mengaplikasikan sifat pangkat logaritma pada baris kelima, maka turunan $\ln x^{2}$ dan $\ln \left(\begin{array}{ll}1 & x\end{array}\right)^{3}$ dapat ditentukan dengan mudah. 


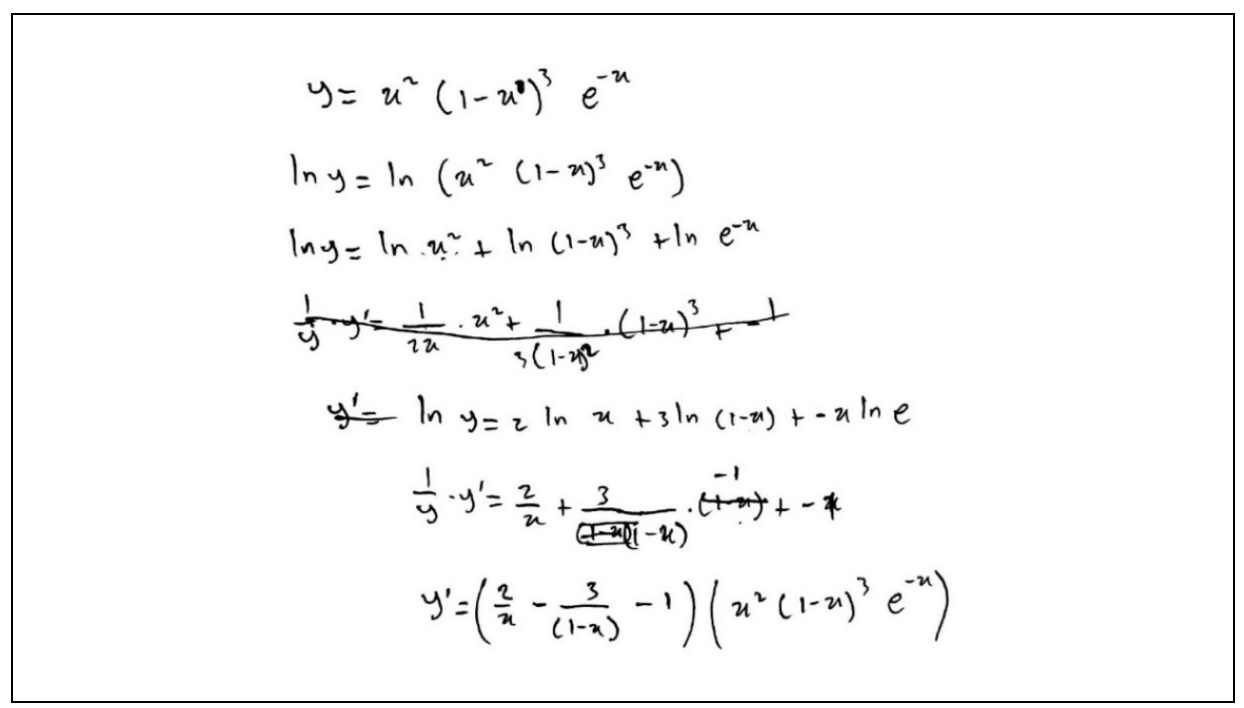

Gambar 5

\subsection{Alasan mengapa mahasiswa cenderung menggunakan metode diferensiasi logaritmik dalam menentukan turunan fungsi}

Berdasarkan data yang diperoleh, terdapat kecenderungan mahasiswa partisipan dalam menggunakan metode diferensiasi logaritmik. Meskipun tidak semua soal tes observasi diselesaikan dengan metode tersebut, namun analisa di bawah ini menjelaskan bahwa metode diferensiasi logaritmik lebih dipilih dalam menyelesaikan soal turunan fungsi tertentu.

Pada gambar 6 di bawah ini terlihat bahwa SP2 melakukan kesalahan saat menentukan turunan fungsi $y=\frac{\left(x^{2}-1\right)^{3}}{x^{2}+1}$. Pada awalnya SP2 mengerjakan soal ini dengan menggunakan aturan diferensiasi pembagian, yaitu jika $y=\frac{u}{v}$ maka $y^{\prime}=\frac{u^{\prime} v-u v \prime}{v^{2}}$. Namun terdapat kesalahan pada bagian turunan dari $\left(\begin{array}{lll}x^{2} & 1\end{array}\right)^{3}$, dimana faktor $2 \mathrm{x}$ lupa dituliskan. SP2 menyadari kesalahannya sendiri dan menuliskan kata "salah" di baris ketiga solusi tersebut. (Gambar 6).

Setelah melakukan kesalahan yang pertama, SP2 mencoba lagi dan masih menggunakan cara yang sama, serta menuliskannya di bawah jawaban pertama. Namun setelah selesai dan dicek kembali ternyata masih ada kesalahan pada jawaban yang kedua, yaitu pada saat memfaktorkan $6 x$, sehingga SP2 menuliskan kembali kata "salah" pada jawaban yang kedua. Pada akhirnya SP2 melakukan cara yang berbeda, yaitu metode diferensiasi logaritmik (Gambar 7). Dapat terlihat pada gambar bahwa SP2 mampu menyelesaikan soal ini dengan baik dan tanpa kesalahan. 


\begin{tabular}{|c|c|}
\hline 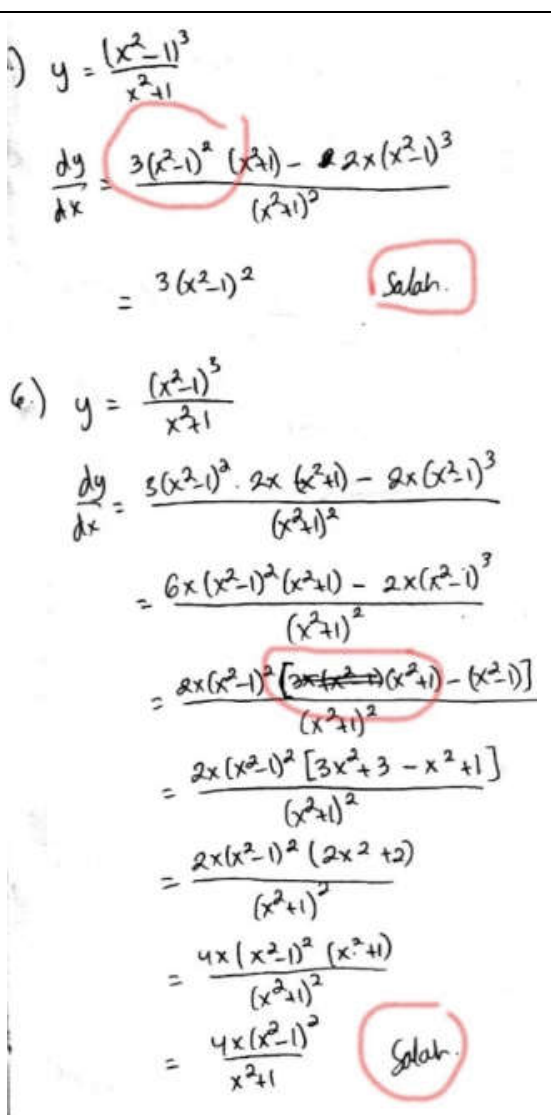 & 6.) $\begin{aligned} y & =\frac{\left(x^{2}-1\right)^{3}}{x^{2}+1} \\
\ln y & =\ln \frac{\left(x^{2}-1\right)^{3}}{x^{2}+1} \\
\ln y & =\ln \left(x^{2}-1\right)^{3}-\ln \left(x^{2}+1\right) \\
\ln y & =3 \ln \left(x^{2}-1\right)-\ln \left(x^{2}+1\right) \\
\frac{1}{y} \cdot \frac{d y}{d x} & =3 \cdot \frac{1}{x^{2}-1} \cdot 2 x-\frac{1}{x^{2}+1} \cdot 2 x \\
\frac{d y}{d x} & =\left[\frac{6 x}{x^{2}-1}-\frac{2 x}{x^{2}+1}\right] y . \\
& =\left[\frac{6 x\left(x^{2}+1\right)-2 x\left(x^{2}-1\right)}{x^{4}-1}\right]\left[\frac{\left(x^{2}-1\right)^{3}}{x^{2}+1}\right] \\
& =\left[\frac{6 x^{3}+6 x-2 x^{3}+2 x}{\left(x^{2}-1\right)\left(x^{2}+1\right)}\right]\left[\frac{\left(x^{2}-1\right)^{3}}{\left(x^{2}+1\right)}\right] \\
& =\frac{\left(4 x^{3}+8 x\right)\left(x^{2}-1\right)^{2}}{\left(x^{2}+1\right)^{2}} \\
& =\frac{4 x\left(x^{2}+2\right)\left(x^{2}-1\right)^{2}}{\left(x^{2}+1\right)^{2}}\end{aligned}$ \\
\hline
\end{tabular}

Gambar 6

Gambar 7

Berikut adalah transkrip wawancara mengenai proses berpikir SP2 dalam mengerjakan soal nomor enam:

\begin{tabular}{|c|c|}
\hline \multicolumn{2}{|c|}{$\begin{array}{c}\text { Peneliti : “Oke, nomor enam sekarang ... salah?” (membaca ada tulisan } \\
\text { salah di lembar jawaban) } \\
\text { "salahnya dimana nih yang pertama?" }\end{array}$} \\
\hline SP2: & $\begin{array}{l}\text { "Salahnya di ... ini gak dikali turunan x kuadrat min satu nya." } \\
\text { (gambar 6) }\end{array}$ \\
\hline Peneliti & "Oke" \\
\hline SP2: & $\begin{array}{l}\text { "Kalo yang ini ... disininya (menunjuk pada baris ketujuh gambar } \\
\text { 6) "Harusnya kan tiga doang ..." }\end{array}$ \\
\hline Peneliti & $\begin{array}{l}\text { "Tapi ini belum ketahuan salahnya ya, jadi kamu lanjutkan sampai } \\
\text { bawah trus kamu cek lagi?" }\end{array}$ \\
\hline SP2: & "Belum, he eh" \\
\hline \multicolumn{2}{|c|}{ Peneliti : "Setelah itu?" } \\
\hline SP2: & "Saya bikin baru lagi." \\
\hline \multicolumn{2}{|c|}{ Peneliti : “Bikin baru? Tapi caranya beda? Kenapa?" } \\
\hline SP2: & “Setelah dipikir pikir pake ini susah, jadi pake In" (tersenyum) \\
\hline \multicolumn{2}{|c|}{ Peneliti : “Kenapa bisa lebih mudah pake In?" } \\
\hline SP2: & "Inget, pake ini kan pangkatnya lebih besar." \\
\hline \multicolumn{2}{|c|}{ Peneliti : "Pangkat apa?" } \\
\hline & $\begin{array}{l}\text { "Ini pangkatnya kan tiga, terus nanti kalo pake In kan bisa pake } \\
\text { yang dikurang" }\left(\ln \frac{a}{b}=\ln a \quad \ln b\right)\end{array}$ \\
\hline $\begin{array}{l}\text { Peneliti } \\
\text { SP2: }\end{array}$ & $\begin{array}{l}\text { "Oke, kemudian... pada saat penyederhanaan ada masalah?" } \\
\text { "enggak" }\end{array}$ \\
\hline
\end{tabular}


Peneliti : "Lebih mudah cara ini (cara uv) atau cara ini (cara In)?"

SP2: $\quad$ "Lebih mudah yang ini" (metode diferensiasi logaritmik)

Berdasarkan potongan transkrip wawancara dan hasil analisis dokumen pada soal nomor enam, dapat dikatakan bahwa mahasiswa cenderung memilih menggunakan metode diferensiasi logaritmik karena lebih mudah dan dapat meminimalisir kesalahan yang timbul akibat ketidaktelitian dalam menggunakan rumus $y^{\prime}=\frac{u^{\prime} v-u v \prime}{v^{2}}$, terutama jika fungsi $y$ melibatkan fungsi $u$ dan $v$ yang perlu menggunakan aturan rantai dalam menentukan turunannya. Lebih lanjut lagi, dengan menggunakan metode diferensiasi logaritmik, bentuk pembagian dapat berubah menjadi bentuk pengurangan, yaitu dengan menggunakan salah satu sifat logaritma, " $\ln \frac{a}{b}=\ln a \ln b "$. Selanjutnya, dengan menggunakan aturan pangkat pada sifat logaritma, yaitu " $\ln a^{r}=r \ln a$ ", maka proses penurunan fungsi selanjutnya dapat dilakukan menjadi lebih mudah dan sederhana.

Data berikut menunjukkan bahwa bentuk fungsi rasional yang melibatkan pangkat pecahan akan lebih mudah diselesaikan dengan menggunakan metode diferensiasi logaritmik. Dengan metode yang sama, SP1 pun dapat menyelesaikan soal nomor tujuh ini dengan baik.

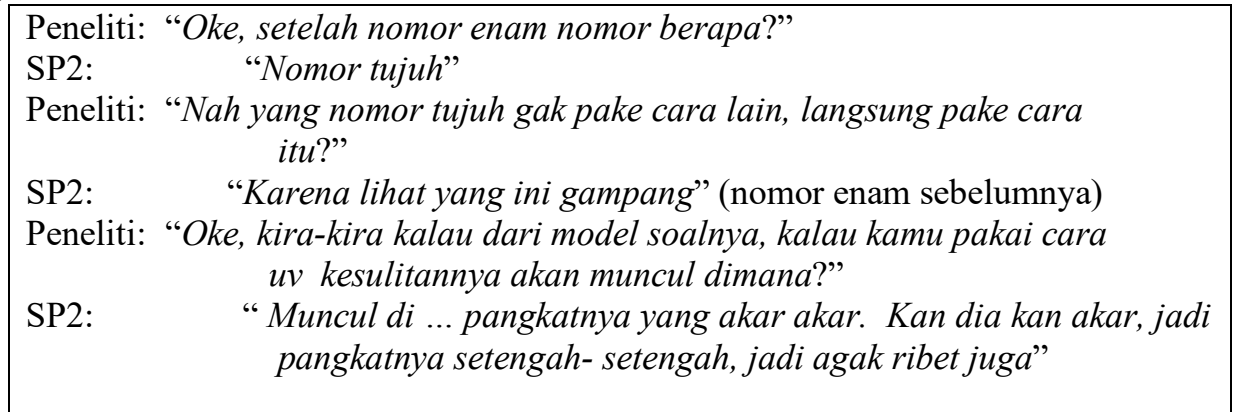

Demikian pula ketika menemui bentuk fungsi perkalian yang melibatkan lebih dari dua faktor, misal $u, v, w$ dan seterusnya. Terlebih lagi jika masing-masing faktor memiliki pangkat pecahan maupun bilangan bulat yang membutuhkan aturan rantai dalam menentukan $u^{\prime}, v^{\prime}$, dan $w^{\prime}$ jika menggunakan aturan diferensiasi perkalian.

\begin{tabular}{|l|l|}
\hline Peneliti: “Nomor satu langsung pake ln, kenapa? \\
SP2: & (tersenyum) "karena ini u v w nya kebanyakan" \\
Peneliti: “Ada tiga faktor ya?, jadi kalau misalnya ini Ibu tutup, hanya ada & $\quad$ dua faktor saja?" \\
SP2: & "Pake yang biasa aja, pake u aksen v \\
\hline
\end{tabular}

Pada bentuk fungsi pangkat dimana basis dan eksponennya melibatkan variabel, maka kedua mahasiswa partisipan tidak menggunakan cara lain selain metode diferensiasi logaritmik, karena tidak ada aturan diferensiasi yang dapat digunakan untuk menentukan turunan fungsi tersebut. Hal inilah yang terlihat dari hasil analisis dokumen milik SP1 (gambar 8) dan SP2 (gambar 9) berikut ini. 


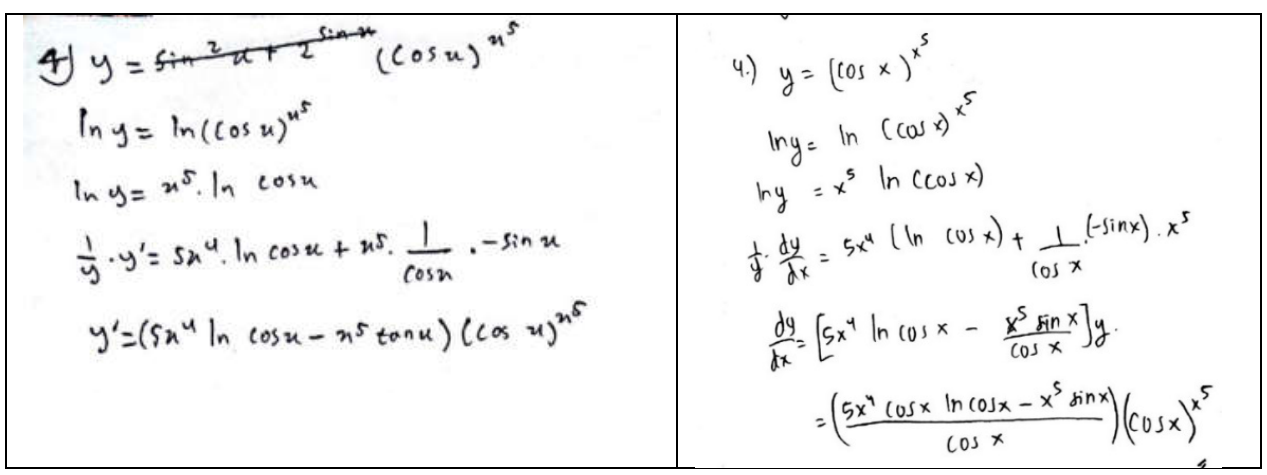

Gambar 8

Gambar 9

Dengan demikian, dapat disimpulkan beberapa alasan mengapa mahasiswa cenderung menggunakan metode diferensiasi logaritmik dalam menentukan turunan fungsi:

1. Metode diferensiasi logaritmik menggunakan sifat logaritma natural yang dapat menyederhanakan bentuk fungsi yang akan diturunkan, sehingga menentukan turunan fungsi menjadi lebih mudah dan sederhana. Berikut sifat logaritma natural yang sering digunakan:
i. $\quad \ln \frac{a}{b}=\ln a \quad \ln b$
ii. $\quad \ln a b=\ln a+\ln b$
iii. $\quad \ln a^{r}=r \ln a$

2. Untuk menghindari kesalahan akibat ketidaktelitian dalam menentukan turunan fungsi. Pada contoh kasus sebelumnya, jika bentuk fungsi yang akan diturunkan melibatkan fungsi rasional maupun fungsi perkalian dengan lebih dari dua faktor, serta diperlukan aturan rantai dalam pengerjaannya, maka akan lebih mudah dikerjakan dengan menggunakan menggunakan metode diferensiasi logaritmik.

\subsection{Karakteristik fungsi yang dapat diturunkan secara lebih mudah dengan menggunakan metode diferensiasi logaritmik}

Berdasarkan penjelasan pada bagian dua diatas, dapat diidentifikasi karakteristik fungsi yang dapat diselesaikan secara lebih mudah dengan menggunakan metode diferensiasi logaritmik diantaranya adalah:

1. Bentuk fungsi rasional, dimana fungsi pada pembilang dan penyebut melibatkan pangkat, baik pangkat bilangan bulat maupun pangkat bentuk pecahan. Jika menggunakan aturan diferensiasi pembagian pada bentuk ini, $y^{\prime}=\frac{u^{\prime} v-u v \prime}{v^{2}}$, kesalahan yang mungkin muncul adalah dalam menentukan turunan dari $u$ dan $v$.

2. Bentuk fungsi perkalian yang terdiri dari lebih dari dua faktor. Demikian pula bentuk fungsi perkalian yang melibatkan pangkat baik bilangan bulat maupun pecahan, serta membutuhkan aturan rantai dalam menentukan $u^{\prime}, v^{\prime}$, maupun $w^{\prime}$ dan seterusnya.

3. Bentuk fungsi pangkat yang melibatkan variabel berpangkat variabel. Misal fungsi $y=(\cos x)^{x^{5}} ; y=x^{\ln x} ; y=\left(x^{\sqrt{x}}\right)$ dan sebagainya.

\section{Kesimpulan}

Berdasarkan hasil analisis diatas, dapat disimpulkan bahwa kesulitan yang dapat terjadi saat menerapkan metode diferensiasi logaritmik dalam menentukan turunan fungsi adalah pada saat menerapkan sifat-sifat logaritma natural. Sifat logaritma tersebut 
adalah "In $a b=\ln a+\ln b$ ", dimana kesalahan yang terjadi adalah menerapkan sifat yang tidak berlaku yaitu, " $\ln a \cdot \ln b=\ln (a+b)$ " . Bentuk kesulitan yang lain adalah saat menerapkan sifat perpangkatan logaritma, yaitu " $\ln a^{r}=r \ln a "$. Dalam hal ini, mahasiswa harus mampu mengidentifikasi komponen basis dan eksponen pada suatu ekspresi logaritma.

Kecenderungan mahasiswa dalam menggunakan metode diferensiasi logaritmik pun terlihat jelas ketika mahasiswa menemui fungsi dengan karakteristik tertentu yang dapat lebih mudah diturunkan dengan mengaplikasikan metode ini. Dengan adanya sifat-sifat logaritma natural, maka langkah diferensiasi menjadi lebih singkat dan mudah. Hal ini dilakukan selain dapat mempercepat dan mempermudah penyelesaian, juga untuk menghindari kesalahan yang dapat terjadi, terutama saat mengoperasikan aturan rantai dalam menggunakan aturan diferensiasi biasa.

Diantara karakteristik fungsi yang dimaksud adalah (1) fungsi rasional dimana komponen pembilang dan penyebutnya merupakan fungsi yang berpangkat, baik pangkat bilangan bulat maupun pangkat pecahan; (2) fungsi perkalian dimana terdapat lebih dari dua faktor dan masing-masing memiliki pangkat; (3) fungsi berpangkat variabel.

Mengingat pentingnya peran kalkulus dalam bidang aplikasi ilmu lain maupun dalam ilmu matematika yang lebih lanjut, maka pembelajaran kalkulus di kelas perlu mendapat perhatian agar mahasiswa mampu memahami konsep dengan baik sekaligus mampu menerapkan teknik-teknik diferensiasi dalam mata kuliah kalkulus diferesial. Mahasiswa diharapkan tidak hanya mampu mengaplikasikan teknik atau aturan diferensiasi saja, melainkan juga harus mampu bersikap fleksibel dalam menentukan strategi atau metode diferensiasi terbaik dan termudah dalam menentukan turunan fungsi.

Dengan demikian, penelitian ini dapat menjadi masukan bagi guru maupun dosen agar dapat menaruh perhatian dalam hal pembelajaran kalkulus di kelas. Pemahaman sifatsifat logaritma maupun sifat logaritma natural dapat menjadi suatu perhatian bagi guru SMA dalam pembelajaran konsep fungsi. Kemampuan mengidentifikasi karakter fungsi yang akan diturunkan serta kemampuan menggunakan metode diferensiasi logaritmik perlu dikembangkan agar mahasiswa dapat lebih fleksibel dalam menentukan turunan fungsi.

Pada hasil penelitian studi kasus ini, tidak ditemukan adanya kesulitan mahasiswa dalam mengaplikasikan metode turunan implisit maupun aturan berantai yang diperlukan dalam prosedur metode diferensiasi logaritmik. Jenis atau karakter soal yang digunakan pun murni soal yang mengukur kemampuan mahasiswa dalam menggunakan strategi dalam menentukan turunan fungsi. Dengan demikian, hasil penelitian ini dapat digunakan untuk mengembangkan penelitian lebih lanjut pada skala yang lebih luas.

\section{Daftar Pustaka}

[1] Varberg, Purcell and Rigdon, Calculus 9th Edition, Pearson, 2006.

[2] C. Rasmussen, K. Marrongelle and M. Borba, "Research on Calculus: what do we know and where do we need to go," ZDM The International Journal of Mathematics Education, vol. 46, pp. 507-515, 2014.

[3] D. Tall, "Dynamics mathematics and the blending of knowledge structures in calculus," ZDM The International Journal of Mathematics Education, vol. 41, pp. 481-492, 2009.

[4] E. Haciomeroglu, L. Aspinwall and N. Presmeg, "Contrasting cases of calculus students' understanding of derivative graphs," Mathematical Thinking and Learning, vol. 12, no. 2, pp. 152-176, 2010. 
[5] N. Hashemi, M. Abu, H. Kahsefi, M. Mokhtar and K. Rahimi, "Designing learning strategy to improve undergraduate students' problem solving in derivatives and integrals: A conceptual framework," Eurasia Journal of Mathematics, Science, and Technology Education, vol. 11, no. 2, pp. 219-230, 2015.

[6] T. M. Apostol, Calculus Volume 1 (2nd edition), United States of America: John Wiley and Sons, Inc, 1967.

[7] M. Denscombe, The Good Research Guide for Small-Scale Social Research Projects, 4 ed., Open University Press, 2010.

[8] B. Chua and E. Wood, "Working with logarithms: students' misconception and errors," The Mathematics Educator, vol. 8, no. 2, pp. 53-70, 2005. 